\title{
Guillain-Barre Syndrome in Postoperative Spine: A Case Report
}

\section{RCS Khandelwal*, Tushar Rathod, Shital Rathod, Arvind Chavan, Chetan Oswal, Kiran Ladkat and Pravin Londhe}

Department of Orthopedics, King Edward VII Memorial Hospital \& Seth G.S. Medical College, Mumbai, India

\begin{abstract}
16 year old male was operated upon for trauma induced L1 burst fracture with complete paraplegia. On $7^{\text {th }}$ postoperative day patient started developing rapidly evolving bilaterally symmetrical ascending areflexic motor paralysis involving shoulder accompanied by tingling dysesthesias in the upper extremities. Thereafter, he developed lower cranial nerve palsy with facial diaparesis. All relevant haematological \& serological tests were not contributory to definite diagnosis and MRI-Spine did not show any abnormality. However, Electrodiagnostic study \& CSF examination supported the diagnosis of Guillain-Barre Syndrome (GBS). Patient was subsequently subjected to plasmapheresis but his condition deteriorated and he succumbed to death on $15^{\text {th }}$ postoperative day.
\end{abstract}

This rare case reports illustrates the importance of watchful expectancy for a neurodeficit that may or may not be related to spine surgery even after critical postoperative period, so that urgent measures can be initiated at the right time in the form of supportive \& curative treatment.

Keywords: Gullain-Barre Syndrome (GBS); Plasmapheresis; Demyelination

\section{Case Report}

16 year old male presented to emergency department with history of fall from height followed by complete paraplegia below T10 level along with sphincteric disturbance. X-ray \& MRI screening confirmed the diagnosis of L1 burst fracture with retropulsion of bony fragment in spinal canal. Patient was operated on the next day with posterior instrumentation (single level) \& canal decompression. Intraoperative \& immediate postoperative period was uneventful. On $7^{\text {th }}$ postoperative day patient started feeling pain \& heaviness in both the upper limb. He developed rapidly evolving areflexic motor paralysis accompanied by tingling dysesthesias in the extremities. Pattern was bilaterally symmetrical ascending paralysis with involvement up to shoulder evolving over hours. Facial diparesis was also present. The lower cranial nerves were involved, leading to bulbar weakness with inability to clear secretions compromising on the airway. Fever and other constitutional symptoms were absent.

Patient was rescreened by MRI to rule out any pathology. Barring fracture pathology imaging did not show any conclusive finding. He was immediately provided with ventilatory assistance. Patient was given plasmapheresis \& other supportive management. As per advice of Neurologist, patient was investigated for routine blood investigation including complete blood count \&ESR (raised in vasculitic neuropathy), detailed oral cavity check-up (to rule out Diphtheria), screening for viral markers (Cytomegalovirus CMV, Herpes etc.), toxic metal (Lead $\&$ Arsenic), porphyria, serum electrophoresis for protein, serum CPK level, vitamin levels \& thyroid profile.

CSF was sent for analysis which showed classical albuminocytological dissociation i.e. elevated CSF protein level $(7 \mathrm{gm} / \mathrm{L})$ without CSF pleocytosis. There was no evidence of pus cells (to rule out bacterial meningitis). Electrodiagnostic study showed demyelination in the form of prolonged distal latencies, conduction velocity slowing and temporal dispersion of compound action potential. This confirmed our diagnosis of Guillain-Barre Syndrome (GBS) that was being suspected on the said clinical profile of the patient. On $15^{\text {th }}$ postoperative day patient succumbed to death due to development of ventilator associated pneumonia \& sepsis. An autopsy was not performed in this patient.

\section{Discussion}

GBS was first described in 1916 by 3 French physicians (Guillain,
Barré, and Strohl) in 2 French soldiers with motor weakness, areflexia, cerebrospinal fluid (CSF) albuminocytological dissociation and diminished deep tendon reflexes [1]. Guillain-Barre Syndrome (GBS) is an acute, frequently severe, and fulminant polyradiculoneuropathy that is autoimmune in nature. Two third of GBS is a postinfectious, immune-mediated disease. GBS is usually preceded by an infection leading to stimulation of Cellular and humoral immune mechanisms [2]. This causes production of antibodies that cross-react with specific gangliosides and glycolipids, such as GM1 and GD1b that are distributed throughout the myelin in the peripheral nervous system [3]. This leads to widespread demyelinating polyneuropathy which may or may not involve cranial nerves.

Most common reported preceding infection is by Campylobacter jejuni. C. jejuni thought to have some antigens on its surface which are supposed to cross react with nerve tissue (molecular mimicry) [4,5]. Host susceptibility is probably one determinant in the development of GBS after infectious illness [6]. Around the world, annual incidence of GBS is 1.2-3 per 100,000 inhabitants [7].

Usually patient with Guillain-Barré Syndrome (GBS) of subtype acute demyelinating polyradiculoneuropathy (AIDP) presents 2-4 weeks following respiratory or gastrointestinal illness with complaints of altered sensation in distal part of extremities and proximal muscle weakness. The weakness ascending and symmetrical in nature affecting lower limb preferentially may progress over hours to days to involve the arms, truncal muscles, cranial nerves, and muscles of respiration. Variants of Guillain-Barré Syndrome may present as pure motor dysfunction including pure autonomic nervous system involvement [8]. Average time frame for clinical features to establish is around 12 days, with $98 \%$ of patients reaching a nadir by 4 weeks. After a plateau phase that ensues, it is followed by gradual symptomatic improvement [8].

*Corresponding author: Ramchandra S. Khandelwal, Department of Orthopedics, King Edward VII Memorial Hospital \& Seth G.S. Medical College, Mumbai, India, E-mail: drrcsk1@gmail.com

Received November 30, 2011; Accepted February 07, 2012; Published February 10, 2012

Citation: Khandelwal RCS, Rathod T, Rathod S, Chavan A, Oswal C et al. (2012) Guillain-Barre Syndrome in Postoperative Spine: A Case Report. J Spine 1:111. doi:10.4172/2165-7939.1000111

Copyright: () 2012 Khandelwal RCS, et al. This is an open-access article distributed under the terms of the Creative Commons Attribution License, which permits unrestricted use, distribution, and reproduction in any medium, provided the original author and source are credited. 
Diagnosis is usually made on clinical ground. Presence of albumino-cytological dissociation on CSF examination along with electrodiagnostic study confirming demylination further supports the diagnosis [9]. On Nerve conduction study, demyelination is characterized by nerve conduction slowing, prolongation of the distal latencies, prolongation of the F-waves, conduction block, and/or temporal dispersion. Even a normal CSF protein level does not rule out GBS especially in early part of disease.

Differential include myelopathies like large epidural hematoma or infection, acute transverse myelopathy, Porphyria polyneuropathy, Most cases of mortality are due to severe autonomic instability or from the complications of prolonged intubation and paralysis [10]. Good supportive care is critical in the treatment of patients with GBS [11]. Intravenous immunoglobulins \& plasmapheresis are two options available to clear out immunoglobulins \& immune complexes present in blood.

Here we are reporting a post operative Guillain-Barre syndrome of subtype Acute Inflammatory Demyelinating Polyradiculopathy (AIDP) in a 16 year old posttraumatic paraplegic It is very uncommon to have neurological deficit postoperatively which is not related to surgery. A probable factor which may cause such a kind of clinical presentation post surgery is large epidural hematoma, abscess or vascular insult to spinal cord. But in our case presentation was on $7^{\text {th }}$ postoperative day with no fever or constitutional symptoms \& imaging was also inconclusive thus ruling out above mentioned etiology. Our patient had classic rapidly evolving bilaterally symmetrical ascending areflexic motor paralysis \& lower cranial nerve palsy with facial diaparesis. These features along with CSF \& Electrodiagnostic picture are suggestive of AIDP variety of GBS.

In literature very few cases of GBS following surgery [12-14] or epidural anaesthesia [15] are reported thus necessitating underlying importance of this entity \& a need for study in a cohort of such patients'. Most of case report show rapid onset of GBS occurring in postoperative period with asymptomatic interval immediately after surgery \& majority of them responded to plasmaphersis [12]. Careful review of literature suggest that post operative GBS appears to occur after all types of surgery without any specific predilection to spine surgery though chances of autosensitisation to neural antigens after spine surgery being higher [15].

In our case there is a high likelihood of either postoperative stress along with preceding asymptomatic infection that might have been responsible for precipitating GBS. There is also an theory of intraoperative release of sensitising neural antigens in predisposed host can precipitate such entity as found by Steiner in group of patients who were administered with epidural anesthesia [15].Thus this case report emphasizes that it is important to observe spinal surgery patient for neurological deficit even after the critical postoperative period so that urgent measures in the form of supportive and curative treatment can be initiated at appropriate time as these cases are known to be reversible.

\section{References}

1. Hughes RA, Cornblath DR (2005) Guillain-Barré syndrome. Lancet 366: 16531666.

2. Jacobs $B C$, Rothbarth $P H$, van der Meché FG, Herbrink $P$, Schmitz PI, et al (1998) The spectrum of antecedent infections in Guillain-Barré syndrome: a case-control study. Neurology 51: 1110-1115.

3. Jacobs BC, Koga M, van Rijs W, Geleijns K, van Doorn PA et al. (2008) Subclass IgG to motor gangliosides related to infection and clinical course in Guillain-Barré syndrome. J Neuroimmunol 194: 181-190.

4. Jacobs BC, van Doorn PA, Schmitz PI, Tio-Gillen AP, Herbrink P, et al. (1996) Campylobacter jejuni infections and anti-GM1 antibodies in Guillain-Barré syndrome. Ann Neurol 40: 181-187.

5. Koga M, Takahashi M, Masuda M, Hirata K, Yuki N (2005) Campylobacter gene polymorphism as a determinant of clinical features of Guillain-Barré syndrome. Neurology 65: 1376-1381.

6. van der Meché FG, Visser LH, Jacobs BC, Endtz HP, Meulstee J, et al. (1997) Guillain-Barré syndrome: multifactorial mechanisms versus defined subgroups. J Infect Dis 176: S99-S102.

7. Winer JB (2001) Guillain Barré syndrome. Mol Pathol 54: 381-385.

8. Hughes RA, Rees JH (1997) Clinical and epidemiologic features of GuillainBarré syndrome. J Infect Dis 176 Suppl 2: S92-98.

9. Albers JW, Kelly JJ Jr (1989) Acquired inflammatory demyelinating polyneuropathies: clinical and electrodiagnostic features. Muscle Nerve 12: 435-451.

10. Maher J, Rutledge F, Remtulla H, Parkes A, Bernardi L, et al. (1995) Neuromuscular disorders associated with failure to wean from the ventilator. Intensive Care Med 21: 737-743.

11. Hughes RA, Wijdicks EF, Benson E, Cornblath DR, Hahn AF, et al. (2005) Supportive care for patients with Guillain-Barré syndrome. Arch Neurol 62: 1194-1198.

12. Riebel GD, Heller JG, Hopkins LC (1995) Guillain-Barré syndrome after an operation on the spine. A case report. J Bone Joint Surg Am 77: 1565-1567.

13. Bale JF Jr, Rote NS, Bloomer LC, Bray PF (1980) Guillain-Barré-like Polyneuropathy after renal transplant: possible association with cytomegalovirus infection. Arch Neurol 37: 784.

14. Stambough JL, Quinlan JG, Swanson JD (1990) Guillain-Barré syndrome following spinal fusion for adult scoliosis. Spine (Phila Pa 1976) 15: 45-46.

15. Steiner I, Argov Z, Cahan C, Abramsky O (1985) Guillain-Barré syndrome after epidural anesthesia: direct nerve root damage may trigger disease. Neurology 35: $1473-1475$. 